\title{
A geographic information system-based analysis of ambulance station coverage area in Samsun, Turkey
}

\author{
Ozlem Terzi ${ }^{1}, \mathrm{MD}$, Aziz Sisman ${ }^{2}$, PhD, Sevgi Canbaz ${ }^{3}, \mathrm{MD}$, Cihad Dündar ${ }^{3}, \mathrm{MD}$, Yıldız $\underline{\text { Peksen }}^{3}$, MD
}

INTRODUCTION The location of ambulance stations are of great importance, as location is a determining factor of whether ambulances are able to respond to emergency calls within the critical period. The aim of the present study was to determine whether the ambulance stations in the provincial centre of Samsun, Turkey, were able to cover their entire operational area within 10 mins of receiving an emergency call.

METHODS This study was based on emergency calls received by the emergency medical services of the study area. Detailed address data from the calls was used to produce thematic maps using the geographic information system (GIS). Buffer analysis was used to determine the adequacy of the stations' locations in relation to the time taken to respond to the emergency calls.

RESULTS In the study area, there were a total of 11,506 emergency ambulance calls made in 2009 , which revealed a call density of 0.7 calls per ha and 23.8 calls per 1,000 population. A total of $75.8 \%$ of the calls were made due to medical reasons, while $11.6 \%$ were related to traffic accidents. The GIS-based investigation revealed that the 10-min coverage areas for the four ambulance stations in the provincial centre of Samsun served $76.9 \%$ of the area and $97.9 \%$ of its population. Of the 10,380 calls for which detailed address data were available, $99.2 \%$ were within the stations' 10-min coverage areas.

CONCLUSION According to the buffer analysis, the ambulance stations in the provincial centre of Samsun are able to reach $97.9 \%$ of the population within the critical 10 -min response time. This study demonstrates that GIS is an indispensable tool for processing and analysing spatial data, which can in turn aid decision-making in the field of geographical epidemiology and public health.

Keywords: ambulance, coverage area, geographic information system, station

\section{INTRODUCTION}

Studies have shown that $10 \%$ of deaths following an accident or injury take place in the first $3-5$ mins, and $54 \%-60 \%$ within the first 30 mins. (1) Thus, ambulance services must send a vehicle to the scene of a medical emergency as fast as possible, since this can affect the outcome of the patient. (2) Initial intervention performed at the scene by qualified personnel, and the use of appropriate and rapid transportation have been reported to significantly reduce the incidence of death and future disability. Such information forms the groundwork for the establishment of an organised first aid and emergency system in many countries. Ambulance services have become one of the most important elements in the emergency medical services (EMS) chain, (3) as they provide first aid and basic life support, as well as rapidly transport the patient to the nearest hospital where advanced life support systems and medical care are available. All around the world, ground ambulance stations are based in health institutions, fire service buildings and other appropriate locations close to regional centres. ${ }^{(4)}$

The most important measure of efficiency for an ambulance system is response time. Response time is defined as the amount of time taken from the time the initial call for medical assistance was made to the time of arrival at the scene. ${ }^{(5-7)}$ The most accurate reflection of EMS performance is the time taken from the first ring of the phone to the time when medical intervention begins. Since the probability of death or permanent disability resulting from accident or disease directly correlates to response time ${ }^{(8)}$ reducing response time is essential. Response time can be reduced by increasing the number of ambulances and personnel, and improving the location of existing stations. However, increasing the number of ambulance stations, ambulances and personnel is not a popular option because of the cost that would be incurred. Hence, an alternative solution would be to ensure that existing ambulance stations and vehicles are optimally located within the area they are expected to cover. ${ }^{(9)}$

Through a generalisation of results, the ambulance industry has suggested that emergent ambulance responses meet a response time criterion of $\leq 8$ mins for at least $90 \%$ of all calls. ${ }^{(7)}$ Pell et al calculated that a reduction in target ambulance response time from 14 mins to 8 mins in $90 \%$ of all calls would increase survival following cardiac arrest from $6 \%$ to $8 \%$, and a response time of 5 mins would increase survival by up to $11 \%$. $^{(10)}$ The American College of Cardiology/ American Heart Association guidelines specify that an electrocardiogram should be obtained and interpreted within 10 mins of arrival to the emergency department in patients with symptoms suspicious of acute coronary syndrome. ${ }^{(11)}$

${ }^{1}$ The Public Health Directorate, Corum, ${ }^{2}$ Faculty of Engineering, Department of Geomatics, ${ }^{3}$ Faculty of Medicine, Department of Public Health, Ondokuz Mayis University, Samsun, Turkey

Correspondence: Dr Ozlem Terzi, Deputy Director, The Public Health Directorate, Corum, Turkey. ozlemzelterzi@hotmail.com 


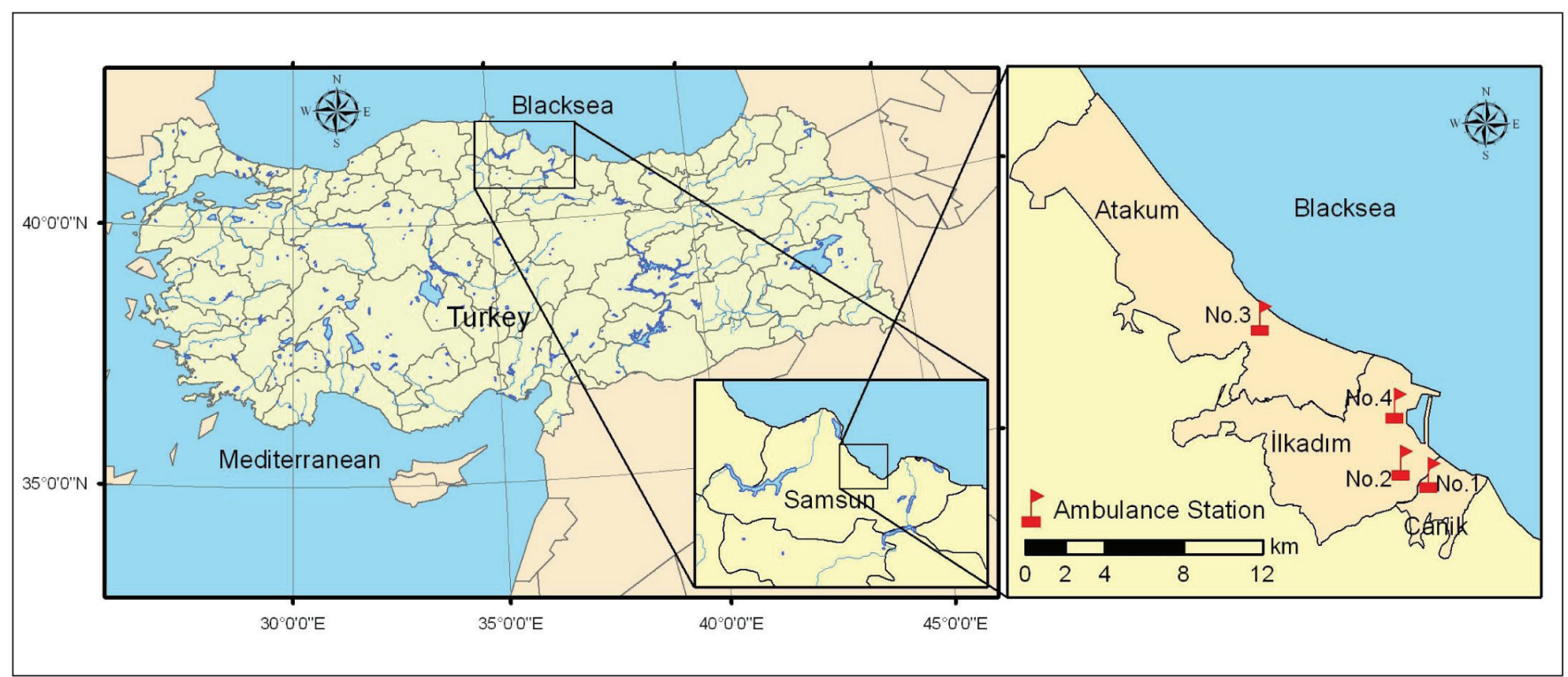

Fig. 1 Map shows the geographical location of the study area.

To determine the coverage of stations and ambulances, there are many widely used, advanced information technologies including the geographic information system (GIS). ${ }^{(12,13)}$ The health sector can be categorised into two distinctive areas - epidemiology and healthcare. Epidemiology, the study of the occurrence of disease (especially in relation to environmental features), is an area in which the traditional analytical tools of GIS are frequently employed. ${ }^{(14)}$ The use of GIS in healthcare is concerned with factors such as hospital and clinic placement, accessibility to these facilities and other services contributing to the health of people. ${ }^{(15)}$

In Turkey, EMS activation starts with a person dialling '112'. The call is then answered by a staff in the command centre, and after the caller has been briefly interviewed, an ambulance is dispatched from the closest station to the patient in need. After the first medical intervention at the scene, the ambulance will be routed to a hospital by the command centre, and the patient will be delivered to the emergency department of that hospital. In Turkey, EMS (i.e. the 112 line) is available nationwide 24 hours a day. The EMS does not belong to any hospital, fire station or rescue team. Instead, the EMS is a branch of the Directorate of Provincial Health and serves all people in need.

In the study area, there are four ambulance stations that are located in appropriate places; the stations have a total of 11 road ambulances and 1 air ambulance (i.e. a helicopter). ${ }^{(16)}$ In an emergency circumstance, the command centre typically sends a road ambulance to the scene. However, if the estimated travel time from the station to the requested location is more than 30 mins, the command centre will send an air ambulance. ${ }^{(16)}$ Each ambulance is staffed by a paramedic and a general practitioner, and the road ambulances are designed and equipped for the transport, advanced treatment and monitoring of patients.

In determining the location of stations in Turkey, factors such as the provision of services for a maximum of 50,000 people, ease of transport facilities, presence of diseases in the region requiring emergency assistance, frequencies of incidents (e.g. traffic and industrial accidents), and the quality, distribution and distances of health institutions offering hospital facilities were taken into account, and the requisite measures put in place accordingly. ${ }^{(17)}$

In light of the above information, this study aimed to determine the number of people and emergency calls covered by the current 10 -min ambulance station coverage area in the provincial centre of Samsun. A GIS buffer analysis was implemented to evaluate ambulance station coverage.

\section{METHODS}

This was a descriptive-type study that covered the provincial centre of Samsun, which lies in the Middle Black Sea region of Turkey, between $41^{\circ} 44^{\prime}$ North and $40^{\circ} 50^{\prime}$ South, and $37^{\circ} 08^{\prime}$ East and $34^{\circ} 25^{\prime}$ West (Fig. 1). The study area consists of three main districts (i.e. İlkadım, Atakum and Canik). It has a population of 482,873, a surface area of $155 \mathrm{~km}^{2}$ and population growth of $1.3 \% .{ }^{(18)}$

The current study includes all ambulance stations (labelled Nos. 1-4 in Fig. 1) and all emergency calls made in the Samsun provincial centre in 2009. The air ambulance was not part of this study. Detailed address data (i.e. local district and street) were obtained for all emergency ambulance callout locations. The positional data of the ambulance stations and emergency calls were also obtained. The administrative borders of the 90 subquarters of the provincial centre of Samsun were digitised within the same coordinate system. All data were inputted into the ArcGIS 9.2 software (Esri, CA, USA). ArcGIS 9.2 is used worldwide by public health specialists and health service planners to produce data using geographic and health data. ${ }^{(19)}$ Call densities were analysed on the basis of subquarter populations and maps were coloured accordingly. In addition, various data for the ambulance response times and 
Table I. Various characteristics of emergency calls in the provincial centre of Samsun, analysed according to districts.

\begin{tabular}{lcccccccc}
\hline District & Population & Area (ha*) & $\begin{array}{c}\text { Inhabitants } \\
\text { per ha* }\end{array}$ & $\begin{array}{c}\text { No. of } \\
\text { stations }\end{array}$ & Total calls & $\begin{array}{c}\text { Calls per 1,000 } \\
\text { persons }\end{array}$ & Calls per ha* \\
\hline Atakum & 105,764 & 7,460 & 14.1 & 1 & 1,861 & 17.6 & 0.2 \\
Canik & 69,363 & 908 & 76.4 & 1 & 2,664 & 38.4 & 2.9 \\
Illkadım & 307,746 & 7,219 & 42.6 & 2 & 6,981 & 22.7 & 0.9 \\
Total & 482,873 & 15,587 & 31.0 & 4 & 11,506 & 23.8 & 0.7 \\
\hline
\end{tabular}

$\star_{1}$ ha $=0.01 \mathrm{~km}^{2}$

Table II. Reasons for emergency calls.

\begin{tabular}{|c|c|c|c|c|c|}
\hline \multirow[t]{2}{*}{ Reason } & \multicolumn{5}{|c|}{ No. of calls (\%) } \\
\hline & $\begin{array}{c}\text { Station No. } 1 \\
(n=2,664)\end{array}$ & $\begin{array}{c}\text { Station No. } 2 \\
(n=3,991)\end{array}$ & $\begin{array}{c}\text { Station No. } 3 \\
(n=1,861)\end{array}$ & $\begin{array}{c}\text { Station No. } 4 \\
(n=2,990)\end{array}$ & $\begin{array}{c}\text { Total } \\
(\mathrm{n}=\mathbf{1 1 , 5 0 6})\end{array}$ \\
\hline Medical reasons & 1,846 (69.3) & $3,206(80.3)$ & $1,386(74.5)$ & $2,278(76.2)$ & $8,716(75.8)$ \\
\hline Traffic accident & 490 (18.4) & $272(6.8)$ & $233(12.5)$ & 340 (11.4) & 1,335 (11.6) \\
\hline Other accidents* & $234(8.8)$ & $377(9.4)$ & $183(9.8)$ & $279(9.3)$ & $1,073(9.3)$ \\
\hline
\end{tabular}

* Includes industrial accidents and injuries. ${ }^{\dagger}$ Includes health precautions, official escort duty and suicide.

calls received were analysed using the Statistical Package for the Social Sciences version 15.0 (SPSS Inc, Chicago, IL, USA) and frequency distributions were established.

Similar studies in the literature were examined in order to evaluate station coverage areas. ${ }^{(5,20,21)}$ In the current study, the aim was to determine the average speed and response time of ambulances within the study area. Accordingly, an average speed of $50 \mathrm{~km} / \mathrm{h}$ was determined for ambulances, bearing in mind factors such as traffic density, driver attitudes regarding giving way to ambulances, road width and road quality. Based on a review of the literature,,$^{(9,10,11)}$ a response time of 10 mins was determined for the EMS in Samsun. The response time of 10 mins did not include medical interventions in the present study - it starts from the time the call for emergency services was received to the time of arrival of the ambulance at the address. A total of 2 mins are allocated for call receipt and setting-out preparations, and 8 mins for the journey of the ambulance from the station to the address. ${ }^{(10,20,22)}$ The duration of 8 mins was used to calculate the distance travelled at a constant speed of $50 \mathrm{~km} / \mathrm{h}$ for the buffer analysis which centred around the ambulance stations. For buffer analysis, the radius ( where radius $=$ the distance travelled in 8 mins by a vehicle moving at $50 \mathrm{~km} / \mathrm{h}$ ) used in determining the 10-min service areas, representing the basis of the research, was calculated by linear correlation and established to be $6.6 \mathrm{~km}$.

\section{RESULTS}

In the study area, a total of 11,506 emergency calls were made in 2009. Analysis of certain characteristics regarding EMS in the districts in the provincial area of Samsun revealed an average of 31.5 emergency calls per day and 1.3 calls per hour. The majority of calls were received from the Illkadım district, but call density was highest in the Canik district (Table I).

There were three main reasons for emergency calls, namely medical reasons, traffic accidents and other accidents (e.g. industrial accidents and injuries) (Table II). These three reasons accounted for $96.7 \%$ of all the emergency calls received. The majority of these calls were made due to medical reasons. A total of 6,981 (60.7\%) emergency calls were addressed by stations No. 2 and No. 4 due to their locations. An examination of the distribution maps of the total calls made due to medical reasons, traffic accidents and other accidents showed that calls due to medical reasons were more frequent in certain areas (increasing where population densities were higher) and traffic accident calls were more frequently made in areas bordering the coast. We also found that in regions with high inner city traffic, there was a supplementary density that stemmed from the use of the orbital road for intercity transportation.

According to the investigations made based on the GIS data obtained, the total 10-min coverage areas for the four stations comprise $76.9 \%$ of the provincial centre of Samsun and $97.9 \%$ of its population (Fig. 2). Of the 11,506 emergency calls to stations, detailed address information was obtained for $10,380(90.2 \%)$. A total of $99.2 \%$ of the calls with available address information were within the stations' 10-min coverage areas (Fig. 3). In terms of the reasons for calls, station catchment areas covered $99.2 \%$ of calls made due to medical reasons, $97.6 \%$ of calls made following traffic accidents and $93.3 \%$ of calls made following other accidents.

\section{DISCUSSION}

There is considerable variation in the population numbers per ambulance station between countries, as well as between regions within countries. According to a study by Cromley and Wei in 2001, ${ }^{(20)}$ the number of inhabitants per ambulance station in northeast Connecticut, USA, was 8,182, while Sasaki et al reported that the population per ambulance station in Nigata, Japan, was 29,777 in 2007.(23) In the current study, the number of inhabitants per ambulance station varied 


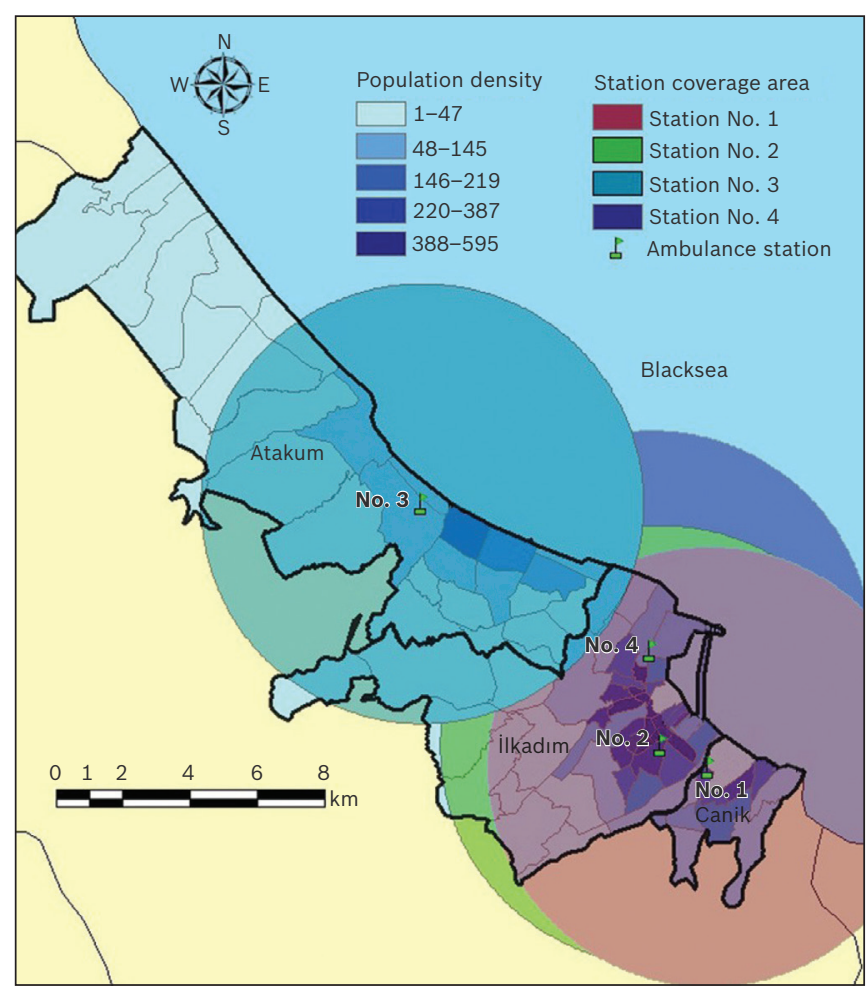

Fig. 2 Map shows the population density of the study area and the four ambulance stations' coverage areas.

between 70,000 and 154,000 in the districts of Atakum, Canik and IIlkadım, which are located within the provincial centre of Samsun (Table I). The ambulance stations in these districts can serve any district in an emergency, depending on the decision of the command centre. The smaller the intended population coverage by an ambulance station, the faster the service provided. With the ongoing increase in population size and dispersion, it is increasingly difficult to achieve adequate response time. ${ }^{(24)}$

Studies have also reported different numbers of emergency calls per head of population. In different cities in Great Britain, the number of calls per 1,000 head of population was reported to be between 60.2 and 140.1, while in North European countries and the United States of America (USA), the numbers were reported to be between 77 and 101 calls per 1,000 individuals and between 11 and 139 calls per 1,000 head of population, respectively. ${ }^{(25,26)}$ In the current study, which was conducted in the provincial centre of Samsun, the number was 23.8 per 1,000 head of population. Another parameter that shows the frequency of use of EMS is the average number of calls daily. For example, an average number of 150.6 calls per day has been reported in Hennepin, Minnesota, USA, a county with a population of around 500,000, while an average number of 361.1 calls per day has been reported in Singapore, a country with a population of about 4.5 million. ${ }^{(27,28)}$ Given a population of approximately 482,000 in the current study in Samsun, the average number of calls daily (i.e. 31.5) may be regarded to be quite low. Number of calls per head of population and average number of calls daily are thought to be influenced by societies' cultural structure, age distribution,

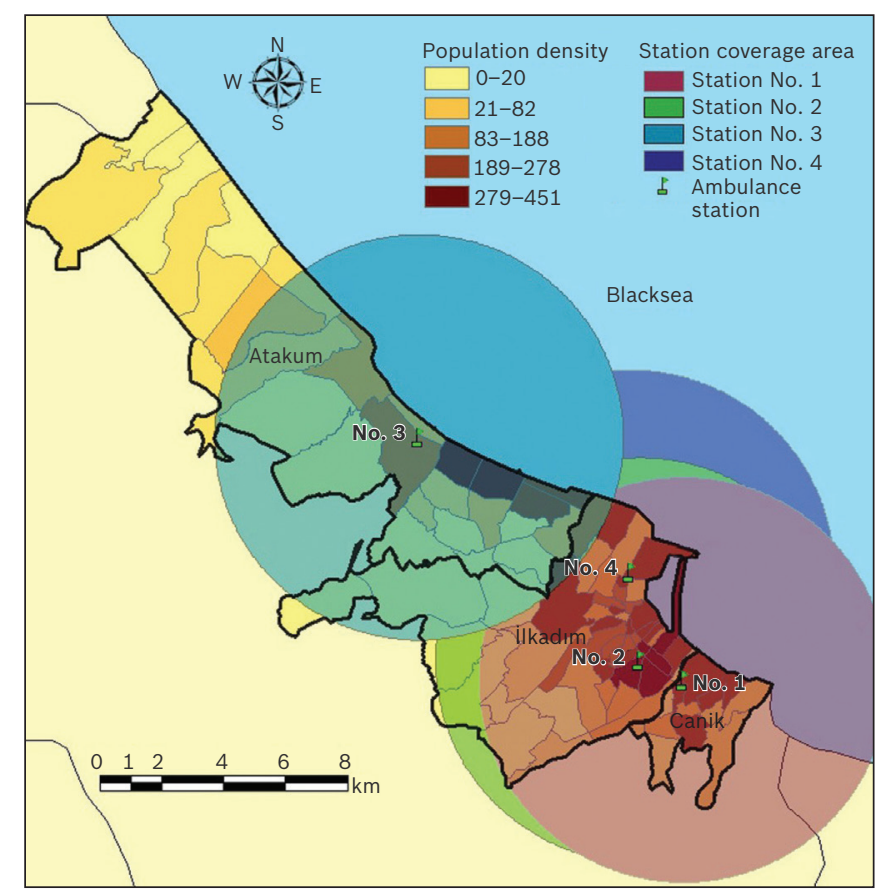

Fig. 3 Map shows total incoming calls within the study area and the four ambulance stations' coverage areas.

frequency of situations requiring emergency assistance within that society, level of awareness of EMS available in the society and knowledge on how to request assistance when required.

With regard to the reasons why calls were made for ambulance assistance, a study conducted in 2003 reported that $59.3 \%$ of patients in the USA were transported to hospitals by ambulances for medical reasons, and $40.7 \%$ for accidentassociated trauma. ${ }^{(29)}$ In a study conducted in Italy, $75.8 \%$ of ambulance calls were made for medical reasons and $17 \%$ for trauma. ${ }^{(30)}$ A study from Norway in 2001 reported that trauma cases constituted $41.0 \%$ of emergency calls. ${ }^{(31)}$ In the current study, medical causes were the prime reason $(69.3 \%-$ $80.3 \%)$ for calls in Samsun, followed by traffic accidents $(6.8 \%-18.4 \%)$.

An analysis of the service areas of all the ambulance stations in the current study showed that there was significant overlap in the coverage areas of stations No. 1, No. 2 and No. 4. Although this might appear to be a negative state of affairs, this overlap may be beneficial to the inhabitants of the areas with high population densities. In other words, when a station providing intensive service for a particular area is occupied with one call, an ambulance and paramedical team from any of the other stations can respond to a subsequent call in that same area. A similar study performed in the provincial capital of Izmir showed that the Konak district and the surrounding area's coverage zones overlap. (21)

Since the city of Samsun extends along the shoreline, the 10-min coverage areas extend directly to the sea. As the station centres also cover more interior regions and serve a wider area, the station centres should be located where the population is most dense. As shown in Fig. 2, the population of the provincial centre of Samsun is concentrated 
Table III. Distribution of response times (data from Samsun Emergency Health Services ${ }^{(16)}$ ).

\begin{tabular}{lccccc}
\hline Duration (mins) & \multicolumn{5}{c}{ No. (\%) } \\
\cline { 2 - 6 } & $\begin{array}{c}\text { Station No. 1 } \\
(\mathbf{n}=\mathbf{2 , 6 6 4 )}\end{array}$ & $\begin{array}{c}\text { Station No. } \mathbf{2} \\
(\mathbf{n}=\mathbf{3 , 9 9 1 )}\end{array}$ & $\begin{array}{c}\text { Station No. 3 } \\
(\mathbf{n}=\mathbf{1 , 8 6 1 )}\end{array}$ & $\begin{array}{c}\text { Station No. 4 } \\
(\mathbf{n}=\mathbf{2 , 9 9 0 )}\end{array}$ & $\begin{array}{c}\text { Total } \\
(\mathbf{n}=\mathbf{1 1}, \mathbf{5 0 6})\end{array}$ \\
\hline $0-10$ & $2,238(84.0)$ & $3,599(90.2)$ & $1,599(85.9)$ & $2,606(87.2)$ & $10,042(87.3)$ \\
$11-20$ & $284(10.7)$ & $196(4.9)$ & $163(8.8)$ & $246(8.2)$ & $889(7.7)$ \\
$\geq 21$ & $142(5.3)$ & $196(4.9)$ & $99(5.3)$ & $138(4.6)$ & $575(5.0)$ \\
\hline
\end{tabular}

in quarters close to the coastal strip. While the 10-min coverage area comprises approximately only $75 \%$ of the provincial centre, the fact that the 10-min coverage area covers almost all of the population and calls received is a positive finding. Only certain subareas in Atakum were not covered by the 10-min coverage areas. The most important criteria in determining ambulance station locations are population density and emergency call density. The subareas of Atakum district did not meet these criteria. However, the future rates of population growth in these areas need to be monitored and evaluated in terms of access to EMS.

In general, the majority of studies pertaining to the location of ambulance stations evaluated whether the location of a new station is appropriate and what the resulting coverage area will be..$^{(5,21,30)}$ For that reason, we found that there was a lack of adequate studies in the literature that could be compared with the current study. However, there is a similar study conducted in the USA, which reported that the ambulances' 10-min service areas covered $80.0 \%$ of the Eastford region and $73.0 \%$ of the Woodstock area. ${ }^{(20)}$ Although research by Cromley and Wei showed coverage levels similar to that of the current study's, comparison to the desired level could not be performed as there was a lack of data regarding the population and call densities. ${ }^{(20)}$ In a similar study in Turkey, Gümüş et al were unable to obtain information regarding the area, population and emergency calls within their study's coverage area. ${ }^{(21)}$

In the current study, data on the response time of the four existing ambulance stations in Samsun was obtained from Samsun Emergency Health Services (Table III). ${ }^{(16)}$ According to the data on response time, arrival at a scene within 10 mins or less varied between $84.0 \%$ and $90.2 \%$. However, the 10 -min service areas covered $99.0 \%$ of cases. This discrepancy may be attributed to factors that negatively impact response times, such as ambulance speed, traffic density, condition of roads used (e.g. main roads, minor roads and dirt tracks) and problems experienced by drivers in locating the addresses.

Our study had some limitations. In Turkey, there are no specific limits to the service region of ambulance stations. When an emergency ambulance call is received by EMS, the ambulance team from the nearest station is dispatched. Hence, no analysis regarding the adequacy of the service area at the station level could be performed; instead, the four stations were evaluated as a whole. Another limitation was that the emergency calls were not logged onto the map via points by geographical location. This was not done as the logging process would be time-consuming and the presence of thousands of small dots would create a visual problem. The maps were therefore prepared by colouring the subquarters according to call densities. The names of all the 90 subquarters were also not included in the map to avoid a visual problem. Ambulances are not able to travel with the same speed on road networks of different quality; they can travel at a speed of up to $100 \mathrm{~km} / \mathrm{h}$ on main roads, and $20 \mathrm{~km} / \mathrm{h}$ on small roads. Thus, another limitation is that although the road networks were not of the same quality over the whole study area, the current study was based on an average travel speed of $50 \mathrm{~km} / \mathrm{h}$ and simple circles of a fixed radius based on the aforementioned average speed. The GIS buffer analysis was used to determine the coverage area of the ambulance stations. Buffer analysis is used for identifying areas surrounding geographic features, and the process involves generating a buffer around existing geographic features and then identifying or selecting features based on whether they fall inside or outside the boundary of the buffer.

In the current study, we analysed the adequacy of the ambulance station service areas in the provincial centre of Samsun using GIS and concluded that there is a high density of emergency calls in Samsun central districts, with medical reasons being the most frequent cause of calls. The 10-min coverage areas of the ambulance stations covered $97.9 \%$ of the population in 2009, and the results of the buffer analysis of the current study coincide with the response time of the ambulance stations in the study area. Considering the coverage areas, the ambulance stations were in the appropriate locations. In the light of the findings of the current study, any change in the location of the ambulance stations cannot be recommended for the near future. Similar studies with a higher resolution of the actual coverage area and real time mapping of the travel speeds of ambulances using GPS loggers should be performed to provide more robust results. As Samsun is rapidly expanding, there may be a need to establish a new ambulance station in an appropriate location in the city.

\section{REFERENCES}

1. Demirhan N. [112 Emergency and first aid services in Turkey and its role in disaster]. In: Demirhan N, ed. 1st ed. Istanbul: Acar Press, 2003. Turkish.

2. Singer $M$, Donoso P. Assessing an ambulance service with queuing theory. Comput Oper Res 2008; 35:2549-60.

3. World Health Organization. Emergency Medical Services Systems in the European Union: Report of an assessment project co-ordinated by 
the World Health Organization [online]. Available at: https://ec.europa. eu/digital-agenda/sites/digital-agenda/files/WHO.pdf Accessed July 25, 2011.

4. Pollak AN, Gulli B, Chatelain L, Stratford C, American Academy of Orthopedic Surgeons Staff. Emergency care and transportation of the sick and injured. 9th ed. Sudbury, Mass: Jones and Bartlett Learning, 2005.

5. Peleg K, Pliskin JS. A geographic information system simulation model of EMS: reducing ambulance response time. Am J of Emerg Med 2004; 22:164-70

6. Sakaklı K. [Measurement and analysis of location of local emergence intervention functions using geographic information systems; the Ankara model (dissertation)]. Ankara, Turkey: Gazi University, 2006. Turkish.

7. Pons PT, Markovchick VJ. Eight minutes or less: does the ambulance response time guideline impact trauma patient outcome? J Emerg Med 2002; 23:43-8.

8. Selim H, Ozkarahan I. A new model in the determination of emergency service vehicle location. J Ind Eng (Turkish Chamber of Mechanical Engineers) 2003; 14:18-27.

9. Coşkun N. Analytic and genetic programming approaches for location problem in emergency service systems. Adana, Turkey: Çukurova University Scientific Institute, 2007.

10. Pell JP, Sirel JM, Marsden AK, Ford I, Cobbe SM. Effect of reducing ambulance response times on deaths from out of hospital cardiac arrest: cohort study. BMJ 2001; 322:1385-8.

11. Zègre-Hemsey J, Sommargren CE, Drew BJ. Initial ECG acquisition within 10 minutes of arrival at the emergency department in persons with chest pain: time and gender differences. J Emerg Nurs 2011; 37:109-12.

12. Turoglu H. [Principles of Geographic Information Systems]. 1st ed. Istanbul: Çantay Press, 2000. Turkish.

13. Yomralıoğlu T. [Basic concepts and applications in geographic information systems]. Trabzon: Geodesis and Photogrammetry Engineering Department Publications, 2000. Turkish.

14. Richards TB, Croner CM, Rushton G, Brown CK, Fowler L. Geographic information systems and public health: mapping the future. Public Health Rep 1999; 114:359-73.

15. Vanmeulebrouk B, Rivett U, Ricketts A, Loudon M. Open source GIS for HIV/AIDS management. Int J Health Geogr 2008; 7:53.

16. Samsun Provincial Ambulance Chief of Staff. [Samsun 112 Emergency Health Services Office] [online]. Available at: http://www.samsun112. saglik.gov.tr. Accessed November 25, 2011. Turkish.

17. Emergence Health Services Administration. [Emergency Health Services Regulation] [online]. Available at: http://www.saglik.gov.tr/TR/belge/1-510/ acil-saglik-hizmetleri-yonetmeligi.html. Accessed July 22, 2011. Turkish.

18. Ministry of the Interior, General Directorate of Civil Registration and
Nationality, Address Registration System TUIK [online]. Available at: http:/ rapor.tuik.gov.tr/reports/rwservlet?adnksdb2\&ENVID=adnksdb2Env\&repo rt=belediye09sonrasi.RDF\&p_il1=55\&p_ilce1=2072\&p_ilce2=2073\&p_ ilce3 $=2074 \&$ p_kod=2\&p_yil=2009\&p_dil=1\&desformat=html. Accessed May 01, 2010.

19. Chang AY, Parrales ME, Jimenez J, et al. Combining Google Earth and GIS mapping technologies in a dengue surveillance system for developing countries. Int J Health Geogr 2009; 8:49.

20. Cromley EK, Wei X. Locating Facilities for EMS Response to Motor Vehicle Collisions [online]. Available at: http://proceedings.esri.com/ library/userconf/health01/papers/hc01_p02f/hc01_p02f.html. Accessed March 14, 2011.

21. Gümüş N, Gündüzoglu G, Askın Y, et al. The distribution of 112 code ambulance stations in the Izmir city center and an investigation into coverage areas using GIS. Istanbul: 4th Geographic Information Systems Awareness Days, 2006.

22. Becker LB, Han BH, Meyer PM, et al. Racial differences in the incidence of cardiac arrest and subsequent survival. The CPR Chicago Project. N Engl J Med 1993; 329:600-6.

23. Sasaki S, Comber AJ, Suzuki H, Brunsdon C. Using genetic algorithms to optimise current and future health planning--the example of ambulance locations. Int J Health Geogr 2010; 9:4.

24. Eryılmaz M. [Emergency Health Services in Turkey: Contemporary Solutions Directed to Need]. Int Emerg Trauma Surg 2007; 13:1-12. Turkish.

25. Peacock PJ, Peacock PL. Emergency call work-load, deprivation, and population density: an investigation into ambulance services across England. J Public Health (Oxf) 2006; 28:111-15.

26. Svenson JE. Patterns of use of emergency medical transport: a populationbased study. Am J Emerg Med 2000; 18:130-4.

27. Hennepin EMS. Emergency Medical Services, Emergency Medical Services Dispatcher [online]. Available at: http://www.hennepinems.org/Home. aspx. Accessed July 24, 2011.

28. Singapore Civil Defence Force. SCDF, The Life Saving Force: Annual Report 2011/12 [online]. Available at: http://www.scdf.gov.sg/ content/dam/scdf_inter/publications/SCDF_AR_2012.pdf. Accessed September 10, 2012.

29. Burt CW, McCaig LF, Valverde RH. Analysis of ambulance transports and diversions among US emergency departments. Ann Emerg Med 2006; 47:317-26.

30. Mendonca FC, Morabito R. Analysing emergency medical service ambulance deployment on a Brazilian highway using the hypercube model. J Oper Res Soc 2001; 52:261-70.

31. Langhelle A, Lossius HM, Silfvast $\mathrm{T}$, et al. International EMS systems: the Nordic countries. Resuscitation 2004; 61:9-21. 